\title{
Vulnerabilidad... ¿hasta cuándo?
}

El Salvador es un país situado sobre la conjunción de dos placas continentales, la placa de Cocos y la placa del Caribe, en el Cinturón de Fuego de América, con la mayor cantidad de volcanes por kilómetro cuadrado de todo el continente, y cruzado por decenas de fallas sísmicas, lo cual ha determinado que periódicamente se sufra de movimientos telúricos, la mayoría imperceptibles, pero algunos (que se repiten cíclicamente) de gran magnilud $\mathrm{e}$ intensidad.

Lo anterior, aunado a las condiciones de pobreza, marginación, migración interna a las ciudades, falta de educación y de políticas adecuadas, hace que el país y su población sean extremadamente propensos a sufrir desastres cada vez que hay un terremolo, una lormenta tropical o un huracán.

Con los recientes terremotos es evidente que las pérdidas humanas constituyen la desgracia más dura que ha enfrentado la población, pero en medio de este profundo dolor perduran otros graves problemas derivados de los eventos sísmicos. Una de las principales consecuencias de los últimos desastres lo constituyen las poblaciones de damnificados, que se estiman en más de millón y medio de personas, quienes perdieron sus viviendas, pertenencias, vestuario y documentos, por tanto necesitan que el Estado les provea de soluciones integrales que les ayuden a recuperar la seguridad personal y familiar.

Es innegable que cuando ocurre una catástrofe natural y ésta se traduce en un desastre social, se altera de manera importante la seguridad de la población afectada en todos los sentidos, desde la vivienda, el trabajo o estudios, los proyectos, el en- torno familiar y social, la propia cotidianeidad de la existencia, etc. sin importar la condición social o económica de los perjudicados, sin embargo, las diversas situaciones de vulnerabilidad social, económica y jurídica de algunos sectores, los vuelven los más desdichados ante estos problemas.

A esta situación de vulnerabilidad, se agrega el hecho que el pais no cuenta con los instrumentos jurídicos idóneos que regulen, tanto la función del Estado como las responsabilidades ciudadanas ante situaciones de interés social, como es la prevención de desastres y mitigación de riesgos, habiéndose avanzado muy poco en ese sentido.

Fue hasta 1998 que la Asamblea Legislativa promulgó el decreto 233, que contenía la Ley del Medio Ambiente, cuyo objetivo es "desarrollar las disposiciones de la Constitución de la República, que se refieren a la protección, conservación y recuperación del medio ambiente... así como también, normar la gestión ambiental, pública y privada y la protección ambiental como obligación básica del Estado".

En el Articulo 55 de la cilada Ley se establece la "obligación de elaborar planes de prevención y contingencia ambiental", la cual es responsabilidad directa del novel Ministerio de Medio Ambiente y Recursos Naturales, en coordinación con el Comité de Emergencia Nacional, una dependencia del Ministerio del Interior, para ser ejecutado por dicho Comité. Para lo anterior, se determina la existencia de un Mapa Nacional de Riesgo Ambiental que determinará las áreas frágiles o de alto riesgo, mapa que si bien es cierto existía con anterioridad a los sucesos del 13 de enero, 13 y 17 de 
febrero del presente año, no sirvió sino como dato para conocimiento, ya que no se instauró ningún plan de prevención o contingencia.

A la negligencia gubernamental se suma la desidia o falta de voluntad política que caracteriza a los mal llamados "padres de la patria". Pocos días después que el huracán Mitch azotara el área oriental de El Salvador, ocasionando numerosos muertos, damnificados, millonarias pérdidas en cultivos e infraestructura vial y de comunicaciones, la Unidad Ecológica Salvadoreña (UNES) presentó a la Asamblea Legislativa un proyecto para la promulgación de la "Ley de Prevención y Mitigación de Desastres y de Protección Civil", proyecto que pasó al archivo sin haber sido siquiera discutido para realizar observaciones y mucho menos, consultas.

Es pasmosa la realidad a la que se han enfrentado cientos de familias de colonias y residenciales relativamente nuevas, quienes se encuentran ante viviendas declaradas inhabilables, sea por su construcción o ubicación, o con daños cuya reparación sobrepasa varios miles de colones, sin recibir respuestas institucionales o de responsabilidad de las constructoras encargadas de los proyectos.

La "Ley de Urbanismo y Construcción" vigente data de 1951, habiéndosele introducido reformas en 1991, año en el cual también se dictó el "Reglamento a la Ley de Urbanismo y Construcciones en lo relativo a Parcelaciones y Urbanizaciones Habitacionales", en el cual se establecen los requisitos para obtener un permiso de parcelación y construcción, así como las normas a cumplirse durante el mismo proceso de realización de las obras, estableciendo además, las sanciones administrativas que se imponen a los infractores de las mismas, que van desde la suspención y clausura de la obra, hasta la demolición total o parcial de las obras, pasando por sanciones económicas, proceso que se lleva a cabo en el Viceministerio de Vivienda y Desarrollo Urbano.

Entre estas normas se establece que previo a la escrituración de los inmucbles, el constructor deberá solicitar la recepción de la obra al Viceministerio, así como el permiso para habitar los mismos. Sin embargo, la realidad demuestra que muchas constructoras obvian este paso, por lo cual, si una vez habitadas las casas, y ya a nombre de sus nuevos propietarios, con hipotecas en cualquiera de los bancos del sistema financiero nacional, se determina el incumplimiento por parte del constructor de las normas técnicas y jurídicas en la realización de la obra, de qué serviría la aplicación de las sanciones administrativas contempladas, cuando el mayor perjudicado sería el comprador. En todo caso, existe una sanción profesional, al retirársele el permiso de constructor, lo cual en los casos que se han dado, se burla al asociarse con otro que sí lo tenga.

Afeclados y asesores jurídicos estudian la posibilidad que las constructoras respondan en una acción por daños y perjuicios, derivada de su negligencia, de conformidad al tílulo XXXV del Código Civil, vigente desde 1859 , específicamente en el Artículo 2080, por el cual, "por regla general todo daño que pueda imputarse a malicia o negligencia de otra persona, debe ser reparado por ésta". Sin embargo, esta acción prescribe en tres años contados desde la perpetración del acto. Otra vía que se analiza es la acción redhibitoria, por la cual el comprador puede pedir rescindir la venta o la rebaja proporcional del precio de la cosa, por vicios ocultos de la cosa vendida (Artículo 1659), acción que prescribe en un plazo de un año a partir de la enirega de la cosa. Así pues, los plazos legales no favorecen a la mayoría de los afectados.

Otro punto en desfavor, es el trámite de los procesos civiles, los cuales avanzan exclusivamente a instancia de la parte interesada, en procedimientos estrictamente escritos, y que a pesar de tener plazos establecidos, pueden durar hasta ocho o diez años, dependiendo de los incidentes y recursos interpuestos por las partes, lo cual hace evidente la necesidad de una profunda reforma que imponga un procedimiento oral.

Importante y necesaria sería una iniciativa que permila promulgar una ley de emergencia que establezca procedimientos sumarios y orales para dirimir los conflictos iniciados a raíz de esta situación.

Hasta antes del Código Penal promulgado el 26 de abril de 1997, y que entró en vigencia el veinte de abril de 1998, no existía en El Salvador responsabilidad penal por acciones contra el Medio Ambiente. Es en este nuevo código que se incorpora el Título $X$ "Delitos Relativos a la Ordenación del Territorio, La Protección de los Recursos Naturales, y al Medio Ambiente", en el cual, entre otras, se establece como conducta punible, las "Construcciones no Autorizadas" (Art. 253 Pn), en 
suelos no urbanizables o de reconocido valor artístico, histórico o cultural, determinándose además, responsabilidad para los funcionarios o empleados públicos que, a sabiendas, informen favorablemente, concedan licencias o autoricen tales construcciones.

Así también, se incorporó el artículo $267 \mathrm{Pn}$., relativo a la infracción de Reglas de Seguridad, en cuyo inciso segundo se establece una sanción de prisión de uno a tres años y multa de treinta a cincuenta días multa para quienes "... en la apertura de pozos o excavaciones, en la construcción de edificios, presas, canalizaciones y obras análogas,... infringiere las reglas de seguridad establecidas, cuya inobservancia pudiere ocasionar resultados catastróficos o poner en peligro la vida, la integridad o la salud de las personas".

Sin embargo, para establecer la responsabilidad penal de todas aquellas personas que no cumplieron con tales reglas de seguridad, se debe tomar en cuenta que deben ser por acciones u omisiones realizadas a partir del día 20 de abril de 1998, ya que si son conductas anteriores a la fecha, no pueden establecerse como delictivas por el principio de irretroactividad de la ley, por la cual ésta no será aplicada a situaciones anteriores a la vigencia de la misma, tomando en cuenta que son delitos nuevos que no existían en el Código Penal derogado.

Sin embargo, la mayoría de afectados teme enfrentarse a las "todopoderosas" constructoras, quienes echarían mano de los mismos abogados de siempre -aquellos que no tienen escrúpulos para utilizar trampas, chantajes y hasta amenazas para ganar los casos a favor de sus "honorables" clientes- así como de "expertos" ingenieros que jurarían y perjurarian sobre la excelente calidad de los suelos y construcciones, en un sistema judicial, senalado recurrentemente de corruplo, débil, e ineficiente, en el cual el dinero y poder es capaz de construir salidas fáciles para los influyentes.

El panorama es aun más desalentador para aquellas familias cuyas residencias datan de treinta años o más, construidas por sus padres o abuelos con materiales de bahareque o adobe, y quienes por falta de recursos, no dan el mantenimiento adecuado a las mismas.

La situación resulta más grave para los habitantes de zonas rurales y urbanas marginales, cuyas viviendas construidas de lámina, cartón o

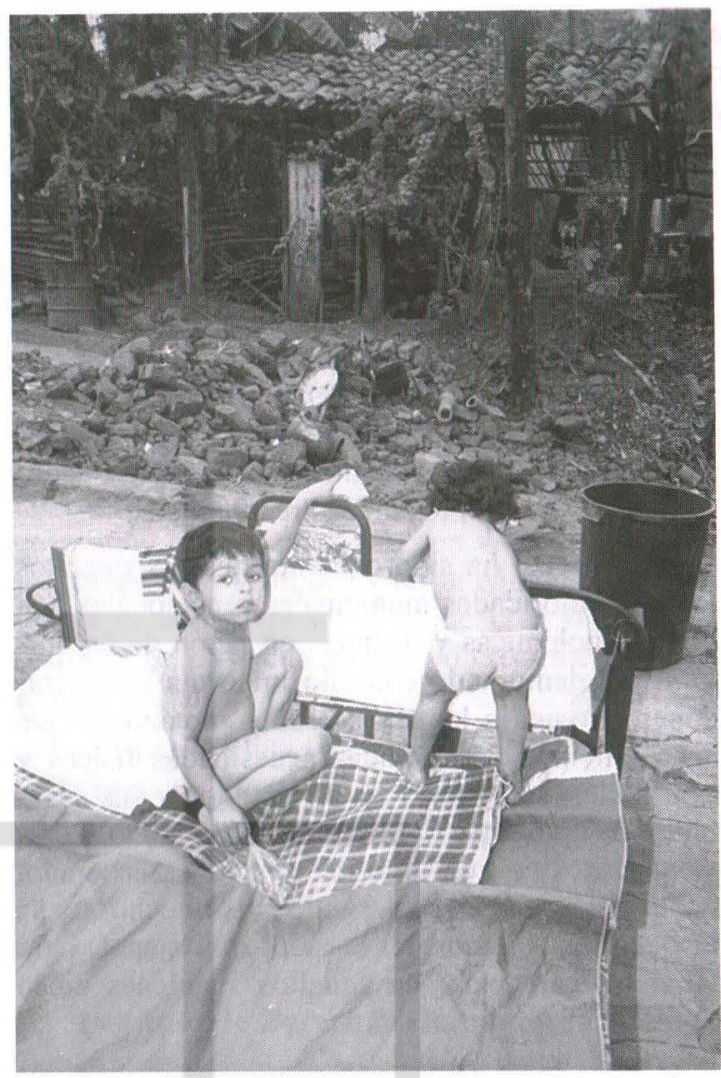

bahareque, se encuentran ubicadas en terrenos que no son propios, en barrancos, laderas de ríos, quebradas o a orillas de peligrosas carreteras.

A lo anterior se suma la poca o nula capacidad de respuesta de las instituciones gubernamentales una vez acaecido el desastre. Escaso personal sin preparación ni educación para intervención en situaciones de crisis y catástrofes, inexistencia de maquinaria idónea o tecnología adecuada, red hospilalaria con infraestructura insegura y sin recursos, hace que la situación se agrave más.

Sin embargo, la responsabilidad estatal no se puede limitar a los parámetros establecidos en la deficiente legislación nacional. Se debe regir por disposiciones constitucionales e internacionales que obligan al Estado a velar por la seguridad de su población, a dictar leyes adecuadas a la realidad y necesidades más urgentes y establecer políticas de prevención y dar respuesta inmediata en casos de catástrofes.

La seguridad jurídica es uno de los derechos fundamentales de todas las personas, establecido 
en el Artículo 2 de la Constitución de la República, por lo cual, el garantizar la conservación y goce del mismo, es una obligación del Estado.

En las actuales circunstancias, tener seguridad significa el derecho de los afectados a que se les otorgue - -sin distinción de ninguna especie - la protección y recursos que requieren mientras recuperan las condiciones que les permitan satisfacer por medios propios sus necesidades esenciales, y es que la protección que debe brindar el Estado debe abarcar el suministro de albergue, alimentación, vestido, atención médica y psicológica, seguridad personal y en los bienes recuperados.

Al respecto ha sido evidente que los distintos tipos de autoridades municipales o nacionales han iniciado polémicas y disputas en razón de colores políticos, demorando con ello importantes aporlaciones o ayuda a los perjudicados, notándose que aún en tiempos de grandes necesidades físicas y espirituales, son incapaces de abandonar sus acostumbradas poses de políticos de inframundo. Parece mentira que aún ante un pueblo desesperado, hambriento, sediento, desnudo y sin techo, no se busquen los caminos del consenso, al menos, para paliar las carencias de aquellos a quienes dicen representar.

Resulta importante señalar que como parte del derecho a la seguridad, es imprescindible tener acceso a la información. Con ello se quiere decir que los afectados tienen derecho de conocer de manera adecuada, oportuna, clara, precisa y veraz, la información disponible sobre aspectos tales como: los fenómenos que propiciaron la situación de desastre, su naturaleza, consecuencias actuales y potenciales, la propia vulnerabilidad a que se encuentran expuestas las comunidades, los riesgos que de la misma pudieran derivarse y todo aquello que sea útil para tomar las decisiones más acertadas.

Es obligatorio para el Estado, además, dar a conocer los planes de prevención, de contingencia, de emergencia, de recuperación y de reconstrucción existentes, los recursos disponibles, los mecanismos de administración y de control de los mismos, así como los instrumentos jurídicos que la población puede utilizar y las instancias e instituciones a las que pueden acudir, fortaleciendo éstas y convirtiéndolas en verdaderos garantes de los derechos humanos.

Pese a lo anterior, el derecho a la información está siendo violentado, ya que los funcionarios res- ponsables no han podido generar confianza en la población, la cual se ve atormentada por diversos rumores, profecías y divulgaciones que se toman más creibles que la versión oficial de los hechos. Mucho se ha insistido también en que se presenten públicamente las credenciales académicas de los "expertos" que han hecho el trabajo de portavoces del gobiemo ante estas calamidades, ya que no basta contar con un apellido extraño para garantizar la base científica que sustente sus afirmaciones.

Otro aspecto determinante al momento de satisfacer el derecho de seguridad de los habitantes aquejados es convertirlos en los principales prolagonistas de los procesos de reconstrucción en sus propias comunidades, propiciando la autogestión para que la población afectada participe de forma activa en la decisión e implementación de estrategias y mecanismos, buscando recuperar el entorno social y familiar y fortalccer la capacidad productiva y económica.

Así pues, la población damnificada tiene derecho a elegir sus propios voceros y representantes ante las distintas instancias y a no ser utilizados ni manipulados por personas, grupos o partidos políti$\cos$.

Sobre estos aspectos se ha observado como algunos políticos han intentado utilizar personas para sus fines. Por ejemplo, la presencia con evidentes propósitos de propaganda de dos personas de la colonia "La Colina" en el anuncio oficial del Presidente de la República sobre las medidas que se tomarán con los damnificados de ese lugar, o las acaloradas aseveraciones, que en un mitin organizado por un diputado de oposición en Ciudad Arce, motivaran airadas protestas contra el Alcalde de dicho municipio, sólo denotan que los políti$\cos$ no dejan que las comunidades se organicen libremente.

Más apremiante se vuelve la situación cuando los afectados no pueden avocarse a quien, por mandato constitucional, es el encargado de defender los derechos de toda la población ante el abuso o negligencia del aparato gubernamental: cl procurador de Derechos Humanos, simple y llanamente. porque su nombramiento no le parece urgente a las y los señores diputados de la Asamblea Legislativa. Más urgente parece ser el dotar con sillas cómodas y modemas a los legisladores, a fin de que puedan permanecer cómodamente durante las largas y casi siempre improductivas sesiones plenarias. 
Los gobernantes, en cuanto a depositarios del poder, están llamados, especialmente en las actuales circunstancias, a ser verdaderos representantes de la población afectada. Ser gobernante requiere, ahora más que nunca, de un sentido de identidad con el pueblo, que es en términos más humanos y reales, el que actualmente sufre las consecuencias de la calamidad.

La urgencia del momento no disculpa ni da licencia para que la ayuda sea definida en forma unilateral. Es necesario abrir los espacios de expresión de los afectados, tomando en cuenta sus opiniones y preocupaciones, asumiendo las realidades propias de cada comunidad, e informando de los riesgos y las posibilidades de reconstrucción.

Aun cuando se sabe que nadie podría evitar fenómenos estriclamente naturales como lo son los terremotos, el Estado no ha cumplido con su deber de garante de los derechos de los habitantes de este país, siendo negligente en sus obligaciones, ya que la ausencia de políticas de prevención y mitigación de riesgos es imputable directamente a éste, no digamos la inexistencia de planes concretos de desarrollo y participación de la sociedad civil, programas de viviendas dignas y legalización de tierras, de educación y acceso a trabajo.
Ante esto, es imprescindible que la sociedad civil se organice solidariamente, a fin de reclamar el respeto de sus derechos económicos, sociales y culturales, adoptando una actitud activa, supervisando el funcionamiento institucional de los entes estatales en su conjunto y elaborando propuestas concretas de fortalecimiento a las instituciones, reformas legales y creación de planes de desarrollo comunal y nacional.

La participación ciudadana en las diferentes etapas del proceso de reconstrucción, debe estar orientada no sólo a la búsqueda de la responsabilidad gubernamental, sino sobre todo a la gestión y autogestión a nivel nacional, con verdaderos aportes y propuestas a fin de evilar la cómoda posición que da el asistencialismo y que crea individuos incapaces de propiciar su propio crecimiento individual y social.

La responsabilidad es, pues, de todas y todos, a fin de que como parte del Estado se logre un verdadero desarrollo humano, basado en los ideales de democracia, responsabilidad y solidaridad, haciendo que, finalmente y para siempre, desaparezca la elerna vulnerabilidad de nuestro pueblo.

Instituto de Derechos Humanos de la UCA 